\section{Buchempfehlung}

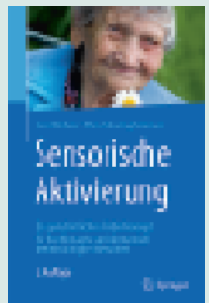

\section{Sensorische Aktivierung}

Ein ganzheitliches Förderkonzept für hochbetagte und demenziell beeinträchtigte Menschen

\section{Lore Wehner, Ylva Schwinghammer}

eBook: ISBN 978-3-662-49799-9, Preis: 22,99 €

Softcover: ISBN 978-3-662-49798-2 Preis: $30,83 €$
2. Auflage, Springer-Verlag 2017, 182 Seiten

Mit dem innovativen ganzheitlichen Förderkonzept „Sensorische Aktivierung“ für hochbetagte Menschen und Menschen mit dementieller Beeinträchtigung sollen wichtige Alltagskompetenzen aufrechterhalten und wiederhergestellt werden. Kernstück des Buches ist der umfangreiche, in der Neuauflage aktualisierte, Praxisteil, der einen Fundus an bereits im Berufsalltag erprobten Stundenbildern zur Gestaltung von Förder- und Aktivierungseinheiten bietet. Diese können als 1:1-Anleitungen oder als Impulsgeber zur Entwicklung eigener Gruppen- und Einzelstunden genutzt werden. Mit Hilfe von zielgerichteter Lebensraumgestaltung, Kurzaktivierung im Pflegealltag und zusätzlichen Förderangeboten können Lebensqualität und Gesundheit positiv beeinflusst und das pflegende Personal entlastet werden. Dies trägt wesentlich zu einer optimalen Nutzung von Ressourcen und zu einer Verbesserung der Betreuungsstandards im Sinne einer qualitativ hochwertigen Aktivierung, sozialen Betreuung und Pflege bei, in deren Mittelpunkt der Mensch steht.

\section{Elisabeth Seidl Preise 2017}

Ausgezeichnete Abschlussarbeiten aus der Pflegewissenschaft

Im Rahmen der Festveranstaltung „25 Jahre Pflegewissenschaft“ im Rudolfinerhaus in Wien Ende September auch die Elisabeth Seidl Preise für herausragende wissenschaftliche Arbeiten aus der Pflege verliehen. Den ersten Platz in der Kategorie Bachelorarbeit erhielt Maria Katherina Job von der UMIT im Kombistudium bei den Barmherzigen Brüdern Wien für Ihre Arbeit „A Family's Nightmare - Parental experience on end-of-life care and the influence of childhood cancer death on parents and siblings“. Den ersten Platz in der Kategorie Masterarbeit erhielt Melanie Mattes von der Universität Wien für Ihre Arbeit: „Komplexes Medikamentenregime bei chronisch Erkrankten und deren Angehörigen“.

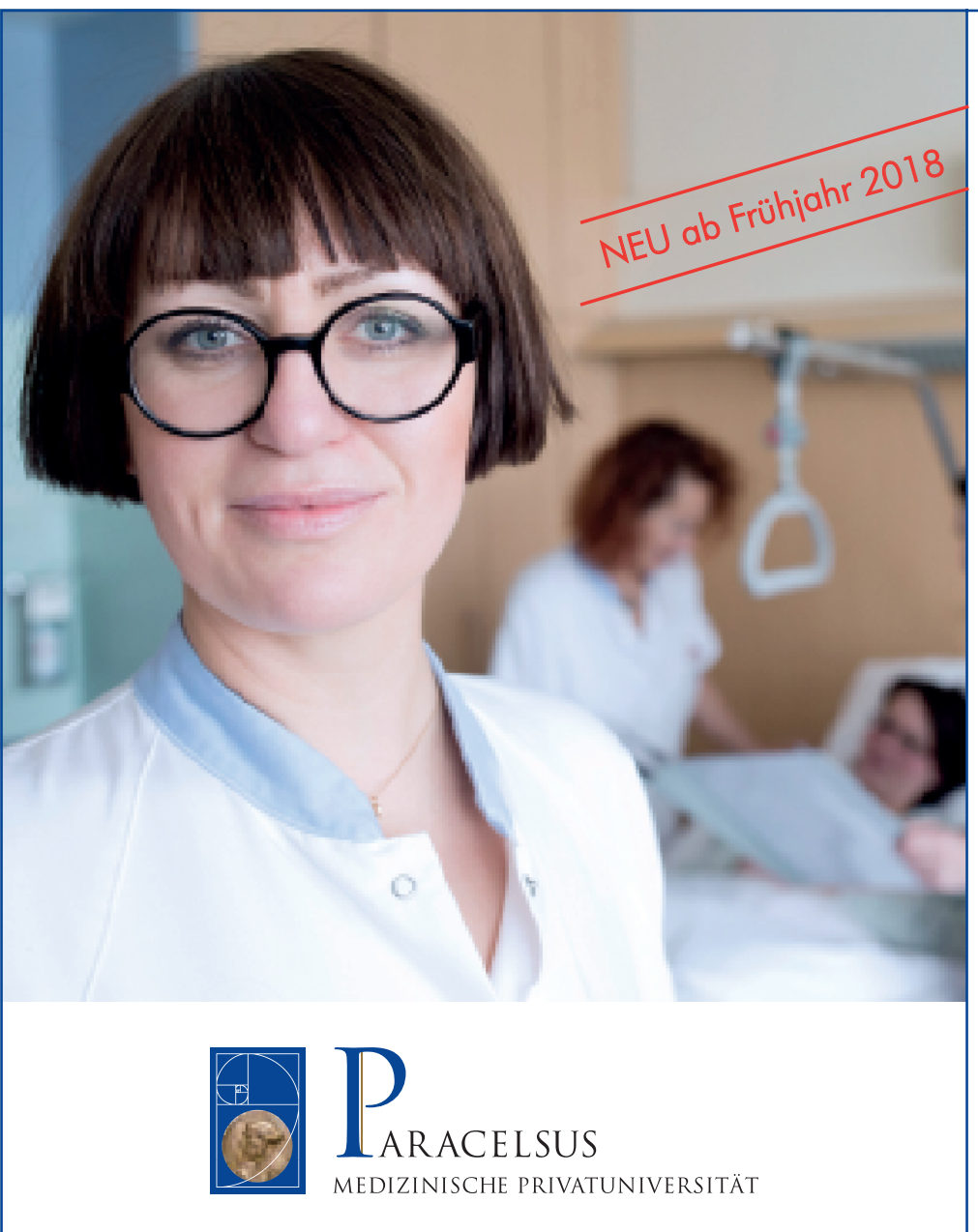

\title{
ADVANCED NURSING PRACTICE
}

Berufsbegleitend, flexibel online studieren und für den modernen Berufsalltag qualifizieren!

\section{Masterstudium*}

Studienform: Online-/Präsenzstudium, berufsbegleitend

Studienbeginn: Jeweils im April

Studiendaver: 2 Jahre, 120 ECTS

Studienplätze: 25

Studienabschluss: Master of Science in Advanced Nursing Practice (acute care oder chronic care)

Studiengebühren: Euro 4.500,- pro Studienjahr

* Vorbehaltlich der Akkreditierung durch die AQ Austria. 